\title{
Chondroitin Sulfate and Hyaluronic Acid Perfusion for Interstitial Cystitis/Bladder Pain Syndrome A Systematic Review and Meta-Analysis
}

\author{
Xiang Xiao, ${ }^{1, \pi}$ Huan Deng, ${ }^{1, \pi}$ Mumba Mulutula Chilufya, ${ }^{1}$ Yizhen Lv, ${ }^{1}$ \\ Yan Zhao, ${ }^{1}$ Jiaxin Liu, ${ }^{1}$ Ziwei Guo, ${ }^{1}$ Lichun Qiao, ${ }^{1}$ Jing Han, ${ }^{1, *}$ \\ Dong Wang, ${ }^{2, *}$ Chengjuan $\mathbf{Q u}^{3}$
}

1. School of Public Health, Xi'an Jiaotong University, Xi'an 710061, Shaanxi, P. R. China

2. Key Laboratory of Biomedical Engineering of Hainan Province, School of Biomedical Engineering, Hainan University, Haikou 570228 , Hainan, P. R. China

3. Department of Odontology, Umeå University, Umeå, 90185, Sweden

q: These authors contributed equally to this work.

*: All corresponding should be sent to Drs. Jing Han and Dong Wang.

Authors' Contact: Xiang Xiao, E-mail: m18064304317@163.com, ORCID: 0000-0003-4053-1706; Huan Deng, E-mail: 957336248@gq.com, ORCID: 0000-0002-4298-3581; Mumba Mulutula Chilufya, E-mail: mumba.mmc@gmail.com, ORCID: 0000-0001-7812-022X; Yizhen Lv, Email: yizhenlv61@163.com, ORCID: 0000-0002-8376-0747; Yan Zhao, E-mail: 2533218374@qq.com, ORCID: 0000-0002-7116-8631; Jiaxin Liu, E-mail: lix17809289471@163.com, ORCID: 0000-0001-9335-6679; Ziwei Guo, E-mail: 1048116303@qq.com, ORCID: 0000-0002-8371840X; Lichun Qiao, E-mail: 978402409@qq.com, ORCID: 0000-0002-6739-0846; Jing Han, E-mail: bbbishop@126.com, ORCID: 00000003-1460-0114; Dong Wang, E-mail: wangdong@hainanu.edu.cn, ORCID: 0000-0002-8209-210X; Chengjuan Qu, E-mail: chengiuan.qu@umu.se, ORCID: 0000-0002-1710-7715.

Funding: This work was funded by the National Natural Science Foundation of China (\#81872567).

DOl: https://doi.org/10.15354/si.21.er001

The authors declare no competing interest.

It has been brought to authors attention that there is a missing part in "Materials and Methods" of the Systematic Review article by Xiao et al., entitled "Chondroitin Sulfate and Hyaluronic Acid Perfusion for Interstitial Cystitis/Bladder Pain Syndrome: A Systematic Review and Meta-Analysis" in the Volume 39, No. 4 of Science Insights (pp.363-373).

The missing part of the "Materials and Methods" is as below:

\section{Population: Patients with IC/BPS.}

Intervention: All patients underwent intravesical HA and/or CS treatment regimen.

Comparison: Improvement in symptoms pre-treatment and post-treatment or other treatment regimen.

Outcome: The primary outcome was the change in visual analogue scale (VAS) for pain symptom from baseline to the followup period; secondary outcomes were the changes in total scores of the O'Leary-Sant Interstitial Cystitis Symptom Index (ICSI) and Problem Index (ICPI), storage symptoms including frequency and urgency, and bladder capacity.

Science Insights, 2021 December 28; Vol. 39, No. 5, pp.419.

(C) 2021 Insights Publisher. All rights reserved. Creative Commons Non Commercial CC BY-NC: This article is distributed under the terms of the Creative Commons
Attribution-NonCommercial 4.0 License which permits non-commercial use, reproduction and distribution of the work without
further permission provided the original work is attributed by the Insights Publisher. 